\title{
Experimental Investigation on Disturbance Wave Velocity and Frequency in Air-Water Horizontal Annular Flow
}

\author{
Andriyanto Setyawan ${ }^{1,3}$, Indarto $^{2} \&$ Deendarlianto $^{2}$ \\ ${ }^{1}$ Graduate Program: Department of Mechanical and Industrial Engineering, Gadjah Mada University, Yogyakarta \\ 55281, Indonesia \\ ${ }^{2}$ Department of Mechanical and Industrial Engineering, Gadjah Mada University, Yogyakarta 55281, Indonesia \\ ${ }^{3}$ Department of Refrigeration and Air Conditioning Engineering, Bandung State Polytechnic, Bandung 40012, \\ Indonesia \\ Correspondence: Andriyanto Setyawan, Department of Refrigeration and Air Conditioning Engineering, \\ Bandung State Polytechnic, Bandung 40012, Indonesia. E-mail: andriyanto@polban.ac.id
}

Received: April 15, 2014

doi:10.5539/mas.v8n4p84
Accepted: April 29, $2014 \quad$ Online Published: June 25, 2014

URL: http://dx.doi.org/10.5539/mas.v8n4p84

\begin{abstract}
The wave characteristics of horizontal air-water annular two-phase flow in 16 and 26-mm-diameter pipe were investigated experimentally using flush-mounted constant electric current method (CECM) sensors and visual observations. The air and water superficial velocities were varied from 12 to $40 \mathrm{~m} / \mathrm{s}$ and 0.05 to $0.2 \mathrm{~m} / \mathrm{s}$, respectively. The flow morphology of annular flow such as the disturbance wave, ripple, wave coalescence, wave development, entrainment, and breakup could be observed. Using cross correlation and power spectral density functions of liquid holdup signals, the wave velocity and frequency were determined. The effect of superficial liquid velocity on the wave velocity and frequency was found to be less significant compared to that of superficial gas velocity. Simple correlations for wave velocity and frequency were also developed.
\end{abstract}

Keywords: horizontal annular flow, liquid holdup, wave velocity, wave frequency, CECM

\section{Introduction}

Annular two-phase flow is easily found in many industrial applications involving phase-change. This flow regime is quite complex, and it is characterized by liquid film on the wall and a gas core containing liquid droplets. For horizontal orientation, due to gravity effect, annular flow is more complicated and it is characterized by the asymmetric distribution of liquid film with thicker liquid flows along the bottom of a tube than on the sides and the top (Shedd, 2001). It also causes the higher droplets concentration in the bottom part than in the other circumferential locations.

Researches for horizontal annular two-phase flow have been carried out over decades. Many aspects have been investigated, including the circumferential liquid film thickness distribution, droplet concentration, secondary flow, pressure drop, and annular flow mechanism. Few theoretical models of such flow have also been developed. However, due to its complexity, it is generally less successful than in those of vertical flow. As a result, the mechanism by which the liquid film is transported to the upper parts of the pipe remains unanswered (Rodriguez, 2009).

Sawant et al. (2008) noted that two types of wave structures are found in annular flow. The first is small ripple wave located on the base film that moves at low velocities, does not have a continuous life, and is considered as not to carry the liquid mass. The second structure, called disturbance wave, has a larger film thickness, usually forming complete rings in the pipe, and travels at a higher velocity. It is responsible for transfer of mass, momentum, and energy along the tube (Sawant, 2008). With a higher amplitude and relatively long-lived structures along the pipe (Shedd, 2001), disturbance waves are responsible for the entrainment of liquid droplets into the gas core when high velocity gas flows and shears the wave. Ripple waves, with the low amplitude surface waves, create interfacial roughness and, therefore, are responsible for the pressure drop. To investigate the effect of disturbance waves on annular flow, the knowledge of wave velocity, frequency, and spacing are required (Schubring \& Shedd, 2008). 
The disturbance wave velocity, or sometimes termed as wave celerity, is usually measured using optical technique and using liquid holdup or film thickness signals employing cross-correlation function. The wave frequency could be determined using power spectral density of liquid holdup or liquid film thickness signals; or determined manually form visual or signal data. The later, however, is very subjective and can lead to great inconsistency in the result of an experiment if it is determined by different workers (Azzopardi, 1986).

In annular flow, the disturbance wave characteristics are not constant throughout the conduit. Wave development, defined as the buildup of a wave when it travels along the conduit, is a common phenomenon in such flow. On the other hand, the reduction of wave amplitude could also be found as result of the entrainment of liquid to the gas core. When travels along conduit, an individual disturbance wave tends to move with a relative constant velocity. If a faster disturbance wave overtakes a slower wave, then the two waves coalesce and usually continue with the speed of the faster wave (Wilkes et al., 1983). This phenomenon is called wave coalescence. The break of a large wave into smaller waves, called the wave breakup, could also be found in annular flow. Due to the occurrences, the wave characteristics of annular flow could be different, even for the same flow geometry, fluid properties, and flow conditions.

The main goal of this paper is to contribute the fundamental data concerning to wave characteristics in air-water horizontal annular two-phase flow as important variables for determining the flow mechanism. In the present paper, the comparison of the experimental results with the previous works will be presented to provide in depth analysis of the wave velocity and frequency and its dependence on the other flow parameters.

\section{Experimental Apparatus}

The experimental rig for this experiment consists of two flow loops with the pipe inner diameters of $16 \mathrm{~mm}$ and $26 \mathrm{~mm}$, each was supplied by air and water from the same compressor and water tank, and utilized the same data acquisition facility. The main raw data desired from this experiment are liquid hold up signals.

\subsection{Flow Loop}

The wave velocity and frequency were extracted from liquid holdup signal measured in an air-water horizontal flow rig shown schematically in Figure 1. The test section was made from acrylic tubes with inner diameters of 26 and $16 \mathrm{~mm}$. To avoid gaps and/or obstructions in the pipe connections, the ends of every pipe section were beveled and the flanges machined. The connections, therefore, were smooth and the flow perturbation was minimized.

Air enters the test section at the upstream from a compressed air supply and water is introduced into the tube through a porous tube wall section. The holdup was measured at a distance of 200 tube diameters from the inlet. It was considered that this length was sufficient for producing fully developed flows. Air and water flow rates to the test section were measured by two rotameter banks. Both phases of fluid were separated in a separator, after which air was released into the atmosphere and water entered a reservoir. A centrifugal pump was used to deliver water from the reservoir to the supply tank. To facilitate visual observation, a visualization box or correction box equipped with DC LCD light was installed in the direction of downstream from the measuring section.

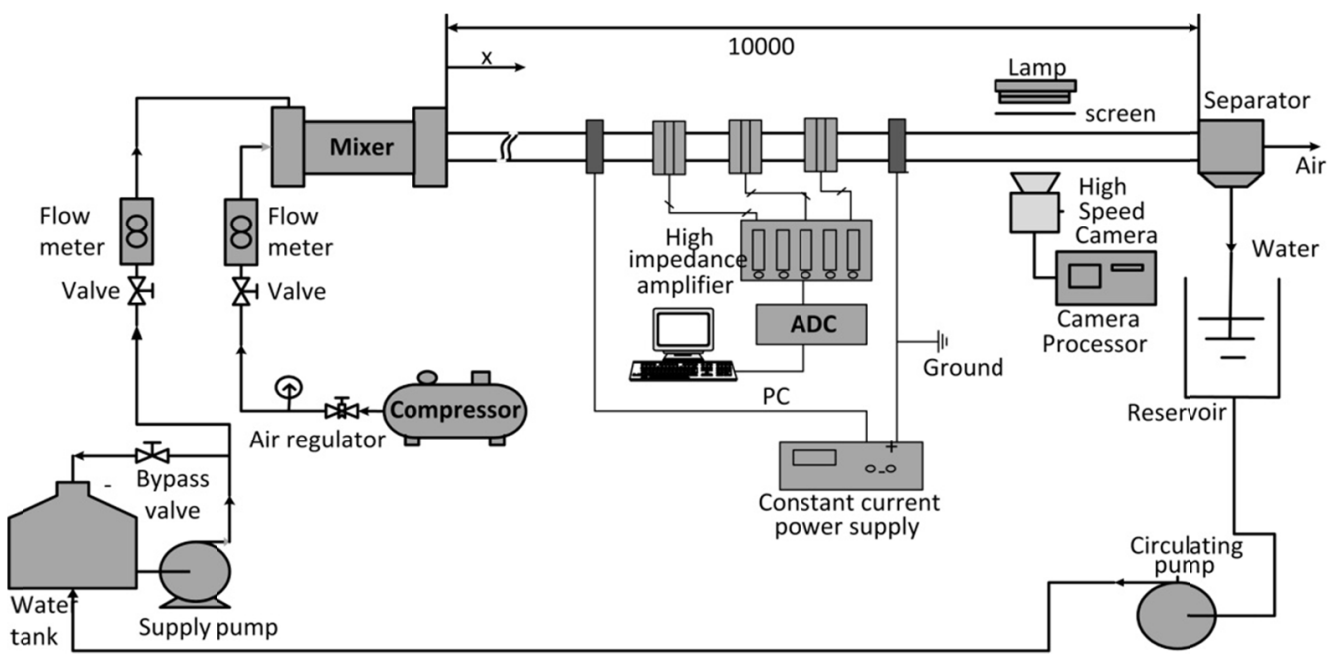

Figure 1. Experimental rig 


\subsection{Liquid Holdup Measurement}

The wave parameters were extracted from the measurement of liquid holdup signal using a constant electric current method (CECM) developed by Fukano (1998). In this technique, a constant electric current is applied from a pair of electrodes, called the power electrodes, as shown clearly in Figure 2. The probes were set in acrylic blocks bored out to the same inner diameter as the test section tube to avoid flow disturbance. The change of liquid holdup was measured by measuring the change of conductance, expressed as a voltage drop, of the two-phase mixture located between the two CECM sensor electrodes.

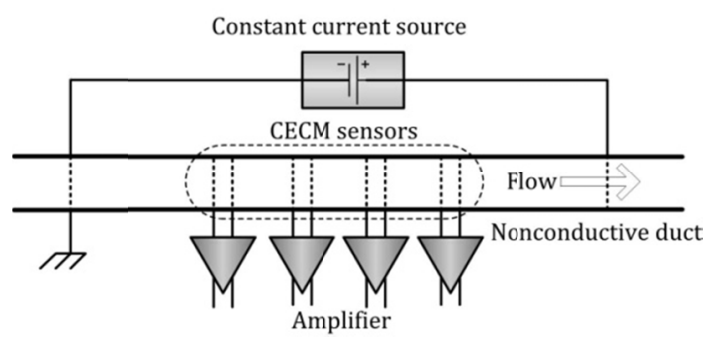

a.

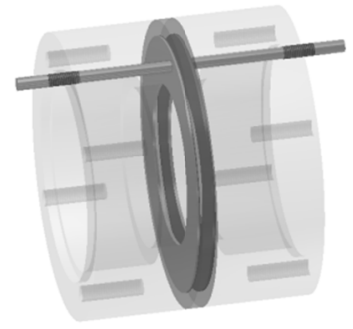

b.

Figure 2. CECM for measuring liquid holdup, a. measurement configuration, b. CECM detail

The voltage drop at the sensor electrodes was fed to a high-input impedance amplifier, so that the constant current was not affected by the presence of the sensor electrodes. The outputs from the amplifier were sent to a computer through an analog to digital converter (ADC) with a sampling rate of $500 \mathrm{~Hz}$. The increase in voltage drop with the increase in electrical resistance due to the existence of gas phase is not affected by the location of gas in the pipe cross section. If the liquid film thickness is very thin, the electric resistance will be higher while the current is constant, resulting in large voltage drop. Therefore, the thinner the film, the larger the voltage drop. It results in higher sensor sensitivity and more accurate holdup measurement.

The interaction among sensor electrodes could be neglected as the outputs were fed to a high impedance amplifier. It means that multiple sensors could be installed in a short distance for simultaneous measurement of liquid holdup at any different axial locations. In this case, only single power source is needed. The other advantage of CECM is that the sensors could be flush-mounted in duct or pipe, thus minimizing the flow disturbance. This sensor has also been successfully utilized by Deendarlianto et al. $(2005,2010)$ and Ousaka et al (2006). Moreover, the calculation method of this sensor can be found in Fukano (1998).

\subsection{Experimental Matrix}

The range of superficial liquid and gas velocities for this experiment are 0.05 to $0.2 \mathrm{~m} / \mathrm{s}$ and 12 to $40 \mathrm{~m} / \mathrm{s}$, respectively. The flow of both air and water were controlled by adjusting the inlet valve for both fluids. Under the given flow conditions, the flow regime observed in this research is mostly annular flow. For the lowest superficial gas velocity, the regimes are transition from wavy to annular and slug to annular flows. The experimental matrix plotted in Mandhane map is described in Figure 3.

\section{Results and Discussion}

\subsection{Flow Transition}

The flow transition from wavy to annular flow was investigated in this experiment under the lowest superficial gas and liquid velocities. Pipe diameter is one of important factor in such flow transition. To investigate it, observations of the flow topology are carried out for the identical gas and liquid superficial velocity for different pipe diameters, $16 \mathrm{~mm}$ and $26 \mathrm{~mm}$. From the visual observation, it was found that the flow pattern at transition are different, even observed at the same gas and liquid superficial velocity $\left(J_{G}\right.$ and $\left.J_{L}\right), 12 \mathrm{~m} / \mathrm{s}$ and $0.05 \mathrm{~m} / \mathrm{s}$, respectively. Figure 4 shows the comparison of flow pattern observed at $16 \mathrm{~mm}$ and $26 \mathrm{~mm}$ pipes. 


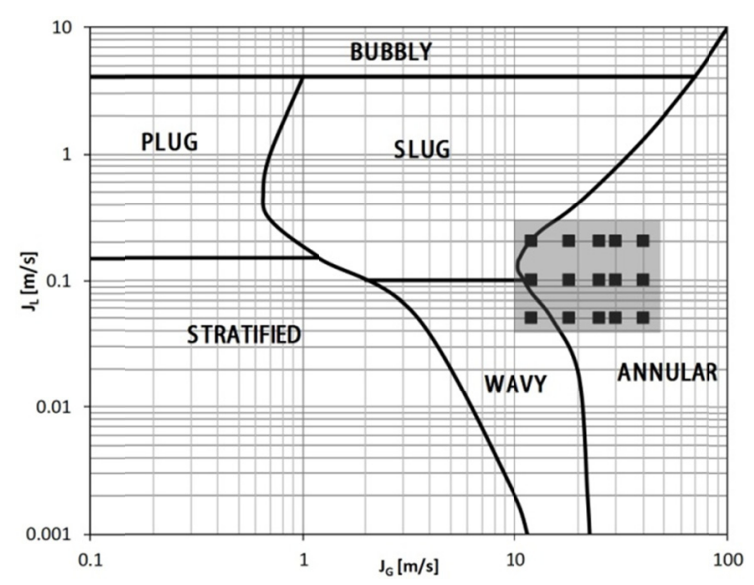

Figure 3. Experimental matrix plotted in Mandhane map

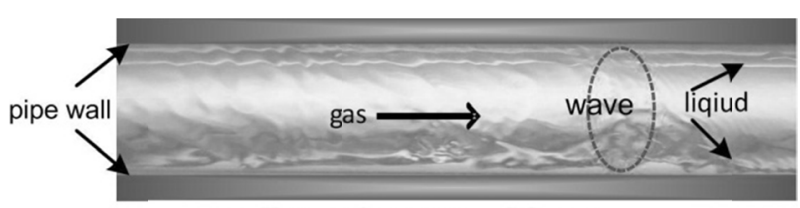

a. Inner diameter $=16 \mathrm{~mm}$

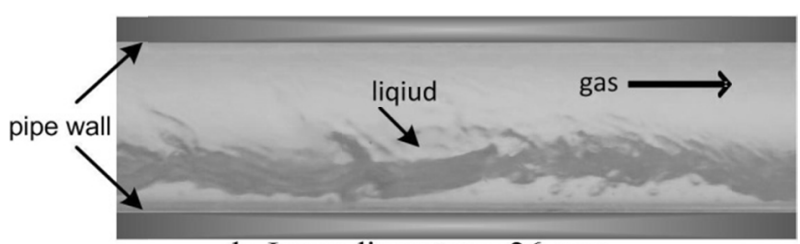

b. Inner diameter $=26 \mathrm{~mm}$

Figure 4. Visualization for $J_{G}=12 \mathrm{~m} / \mathrm{s}$ and $J_{L}=0.05 \mathrm{~m} / \mathrm{s}$ for $16 \mathrm{~mm}$ pipe and $26 \mathrm{~mm}$ pipe

As shown in Figure 4a, an annular flow pattern has been fully formed for pipe diameter of $16 \mathrm{~mm}$. On the other hand, the pattern has not been fully formed at pipe diameter of $26 \mathrm{~mm}$ for the same superficial gas and liquid velocity. In this case, the liquid covers only the lower half of the inner pipe wall, while the upper part of the pipe remains dry. The need for higher gas velocity to develop the annular flow for larger pipe diameter is in agreement with Weisman et al. (1979), who conducted experiment using pipe diameters from $12 \mathrm{~mm}$ to $50 \mathrm{~mm}$. The experimental result of Lin and Hanratty (1987) using $25.4 \mathrm{~mm}$ and $95.3 \mathrm{~mm}$ pipes also supports the effect of diameter. Figure 4, therefore, shows the significant effect of the inner pipe diameter on the flow pattern.

\subsection{Annular Flow Topology}

The existence of disturbance wave and ripple wave in annular flow could be observed using the CECM as well as video camera (Figure 5). As the superficial liquid velocity increases, the amplitude of disturbance wave, as well as the liquid holdup $(\eta)$, will also increase. On the other hand, the increase of superficial gas velocity results in a smaller liquid holdup and wave amplitude. 


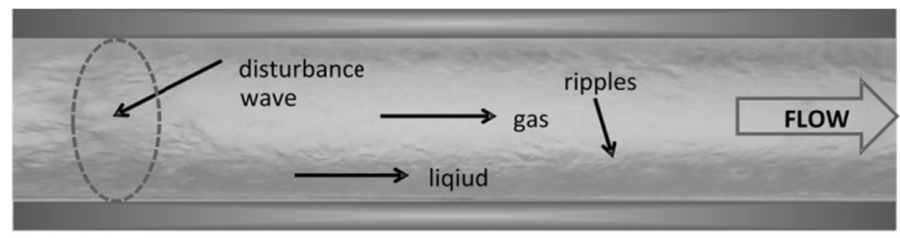

a. Interfacial behavior

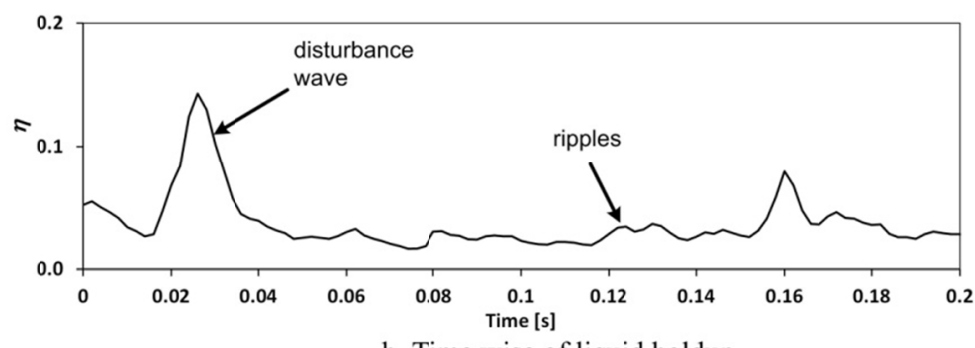

b. Time wise of liquid holdup

Figure 5. Disturbance and ripple waves in $26 \mathrm{~mm}$ pipe $\left(J_{G}=25 \mathrm{~m} / \mathrm{s}, J_{L}=0.2 \mathrm{~m} / \mathrm{s}\right)$

\subsection{Wave Coalescence and Breakup}

The transport of liquid film in the pipe wall could be traced from the liquid holdup signals. Figure 6 shows the typical trace of liquid holdup signals sensed by sensor 1 (upstream) and 2 (downstream). It is shown that the signals detected by sensor 2 are not necessarily similar to those of sensor 1 . The height and the lifetime of the wave could be changed when it travels along the pipe. If the amplitude of the wave sensed by sensor 2 is higher than those of sensor 1, it indicates that the wave "grows", and the phenomenon is called the wave development (denoted by WD in Figure 6). The droplet entrainment (DE), in which a portion of liquid is entrained in the gas core when high velocity of gas flows and shears the gas-liquid interface at wave crest, is indicated by the reduction of wave height. The wave coalescence (WC), usually results in a single wave with larger amplitude and energy. The break of a large wave into smaller waves, called the wave breakup or breaking wave (BW), is also observed in this experiment.

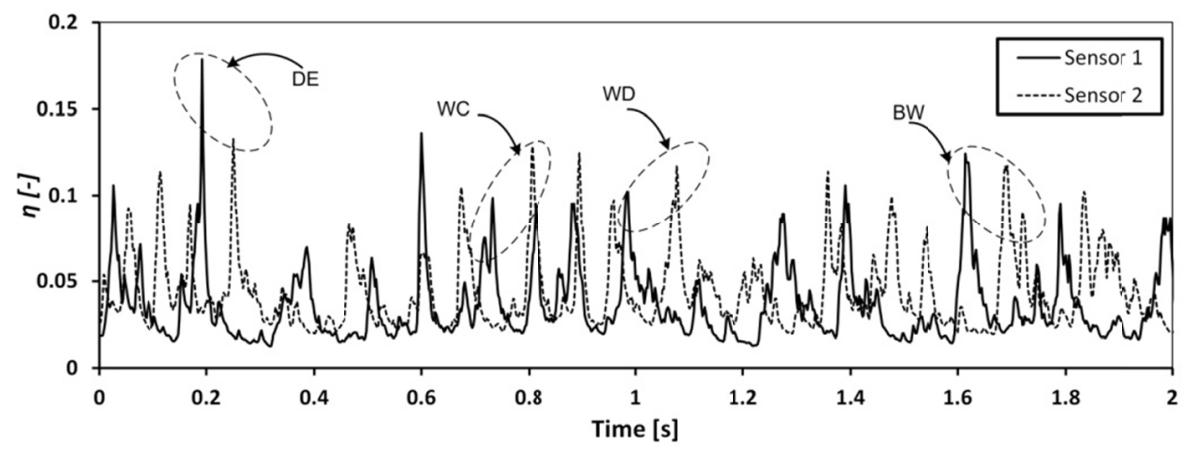

Figure 6. Morphology of annular flow

$\mathrm{WD}=$ Wave development, $\mathrm{DE}=$ droplet entrainment, $\mathrm{WC}=$ wave coalescence, $\mathrm{BW}=$ wave break up.

\subsection{Wave Velocity}

The holdup signal sensed by the downstream sensor (sensor 2) is delayed by several milliseconds compared to those of sensor 1, depending on the velocity of the liquid film. If the time delay and the distance between the sensors are known, the wave velocity $\left(C_{W}\right)$ can be calculated as a ratio of the distance to the time delay. To determine the time delay, a cross correlation function (CCF) of two holdup signals resulted from sensor 1 and 2 is used. Figure 7 shows the result of CCF for superficial gas velocity, of $40 \mathrm{~m} / \mathrm{s}$ and superficial liquid velocity, of $0.05 \mathrm{~m} / \mathrm{s}$, respectively. For this flow condition, the CCF shows that time lag for the holdup signals is $0.048 \mathrm{~s}$. With the sensors spaced $215 \mathrm{~mm}$ apart, then the wave velocity is found to be $4.48 \mathrm{~m} / \mathrm{s}$. The wave velocities for the other flow conditions could be calculated using the similar method. 
For the predetermined range of superficial gas and liquid velocity, the wave velocity ranges from 1.54 to 5.12 $\mathrm{m} / \mathrm{s}$ for $16 \mathrm{~mm}$ pipe and 1.47 to $4.67 \mathrm{~m} / \mathrm{s}$ for $26 \mathrm{~mm}$ pipe. The wave velocity increases with the increase of superficial gas velocity (Figure 8), because at the higher the air velocity, the shear force at the gas-liquid interface is also higher, resulting in higher liquid film flowing in the pipe. For $16 \mathrm{~mm}$ pipe, if the gas velocity is increased from 12 to $18 \mathrm{~m} / \mathrm{s}$ (or by a factor of 1.5) under a constant superficial liquid velocity of $0.05 \mathrm{~m} / \mathrm{s}$, the wave velocity increases by a factor of 1.9 . For $26 \mathrm{~mm}$ pipe, the same increase of gas velocity resulting in the increase of wave velocity by a factor of 1.43. The experiment of Jayanti et al. (1990) with $32 \mathrm{~mm}$ ID pipe showed that the wave velocity increased by a factor of 1.6 if the superficial gas velocity increased by a factor of 1.52 under constant superficial liquid velocity of $0.08 \mathrm{~m} / \mathrm{s}$. Using $50.8 \mathrm{~mm}$ ID pipe, Paras and Karabelas (1991) showed that the wave velocity increased by a factor of 1.36 when the superficial gas velocity was increased by a factor of 1.52 under a constant superficial liquid velocity of $0.06 \mathrm{~m} / \mathrm{s}$. Experiment by Mantilla (2008) with 2-inch and 6-inch pipes also showed that wave velocity increases significantly with the increase of gas velocity. For low superficial liquid velocity and high gas velocity, however, he showed that the wave velocity tends to a constant value.

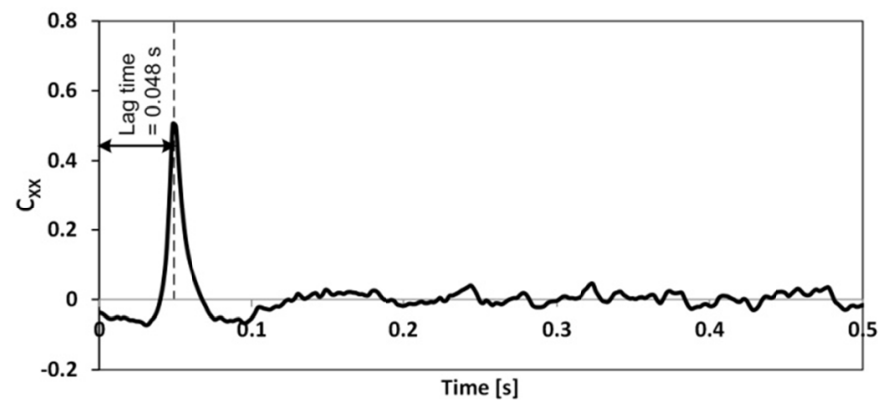

Figure 7. Cross-correlation function of holdup signal $J_{G}=40 \mathrm{~m} / \mathrm{s}$ and $J_{L}=0.05 \mathrm{~m} / \mathrm{s}$

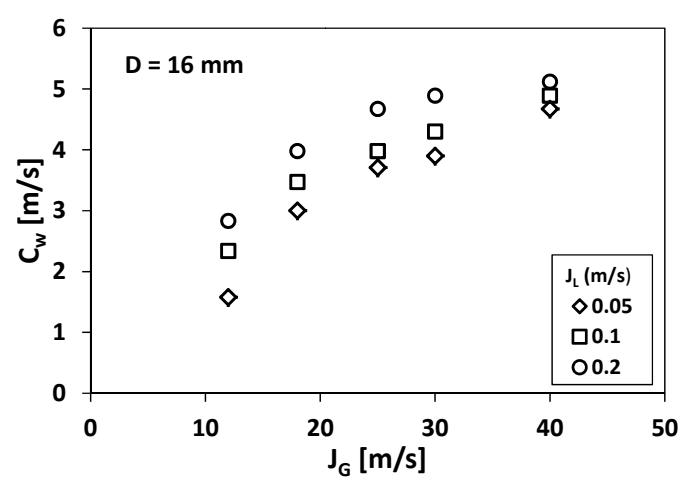

a. Inner diameter $=16 \mathrm{~mm}$

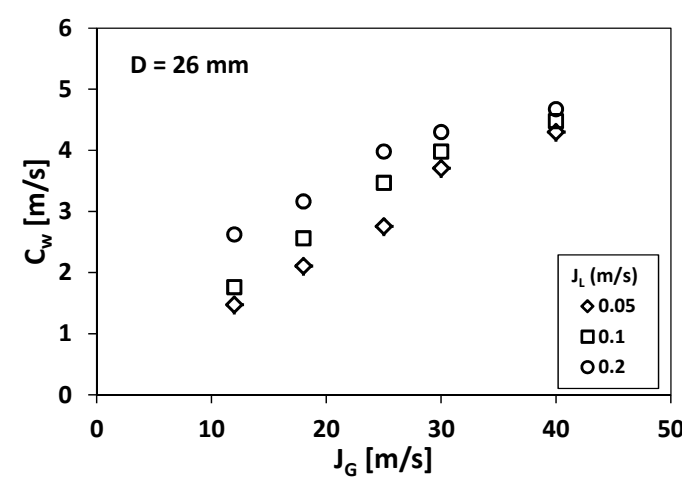

b. Inner diameter $=26 \mathrm{~mm}$

Figure 8 . Effect of superficial gas and liquid velocities on wave velocity

From Figure 8, it is also shown that at a higher gas velocity, the effect of superficial gas velocity on the wave of velocity is less significant than that of low gas velocity $\left(J_{G}<25 \mathrm{~m} / \mathrm{s}\right)$. This is in agreement with Schubbring (2009), Han et al. (2006), and Sawant et al. (2008). A slightly different result was proposed by Azzopardi (1986), in which the effect of gas velocity to wave velocity is almost proportionally linear.

The effect of the superficial liquid velocity is less significant compared to those of superficial gas velocity. As an illustration, in this experiment, the wave velocity increases by a factor of 2.35 if the superficial gas velocity is increased from $12 \mathrm{~m} / \mathrm{s}$ to $25 \mathrm{~m} / \mathrm{s}$ (by a factor of 2.08 ) under superficial liquid velocity of $0.05 \mathrm{~m} / \mathrm{s}$ for $16 \mathrm{~mm}$ pipe. On the other hand, if the superficial liquid velocity is increased from $0.05 \mathrm{~m} / \mathrm{s}$ to $0.1 \mathrm{~m} / \mathrm{s}$, the average increment of wave velocity is only $17 \%$. Further increase of the superficial liquid velocity to $0.2 \mathrm{~m} / \mathrm{s}(400 \%)$ would only give an increase of wave velocity of $35 \%$.

The range of wave velocity from 2.4 to $6 \mathrm{~m} / \mathrm{s}$ has been reported by Schubring and Shedd (2008) for their experiment with $26.3 \mathrm{~mm}$ ID pipe using superficial liquid and gas velocities of 0.04 to $0.39 \mathrm{~m} / \mathrm{s}$ and 32 to $91 \mathrm{~m} / \mathrm{s}$. 
For smaller pipes ( 8.8 and $15.1 \mathrm{~mm}$ ), the wave velocities are in the range of 1.97 to $8.37 \mathrm{~m} / \mathrm{s}$ when the superficial liquid velocity is set from 0.05 to $0.2 \mathrm{~m} / \mathrm{s}$. The correlation for the wave velocity of the three pipe diameters used in their experiment is expressed as follows:

$$
C_{w, s s}=0.42 \frac{J_{G}}{\sqrt{x}} R e_{G}^{-0.25}
$$

The similar correlation from Ousaka et al. (1992) is given by

$$
C_{w, \text { Ousaka }}=3.0 J_{L}\left(\frac{R e_{G}}{R e_{L}}\right)^{0.78}
$$

In the last correlation, the effect of liquid velocity on wave velocity is noticed as a proportionally linear.

In comparison to the present work, Equation (1) results in mean absolute errors (MAE) of $14.8 \%$ for $16 \mathrm{~mm}$ pipe and $29.6 \%$ for $26 \mathrm{~mm}$ pipe. Equation (2) gives MAE of $20.7 \%$ and $23.3 \%$ for $16 \mathrm{~mm}$ and $26 \mathrm{~mm}$ pipe, respectively.

Using similar form of Schubring and Shedd (2008), the best correlation for the present work for wave velocity for $16 \mathrm{~mm}$ and $26 \mathrm{~mm}$ pipes, judged by the smallest MAE, is given by

$$
C_{w, \text { corr }}=0.34 \frac{J_{G}}{\sqrt{x}} R e_{G}^{-0.2}
$$

Here, the effects of superficial gas velocity and flow quality on the wave velocity are similar to those of Schubring and Shedd (2008). The gas Reynolds number, however, is considered less significant in the developed correlation. For the inner pipe diameters of $16 \mathrm{~mm}$ and $26 \mathrm{~mm}$, this correlation gives MAE of $13.4 \%$ and $9.4 \%$, respectively, and the overall MAE for both diameters is $11.4 \%$, as shown clearly in Figure 9.

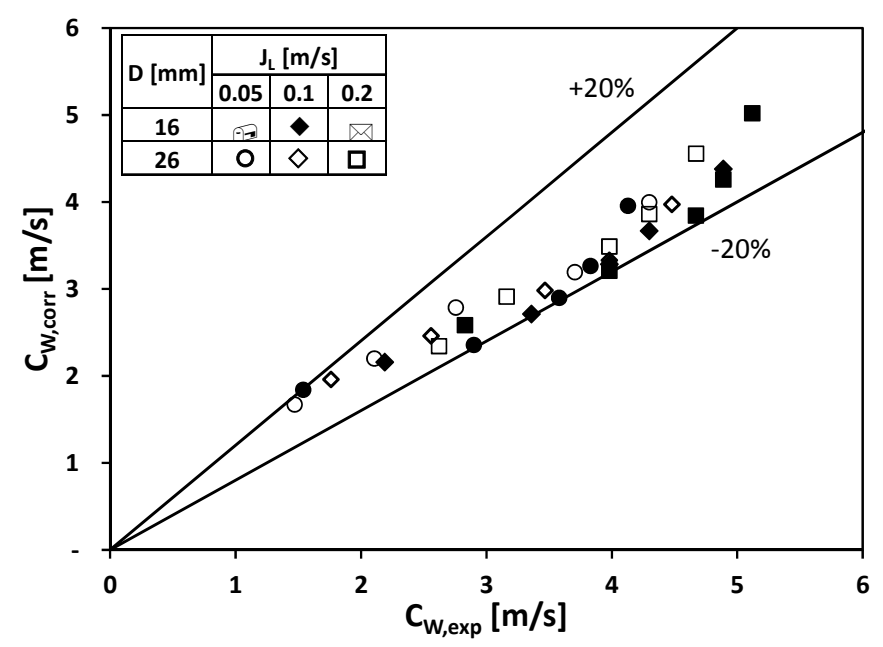

Figure 9. Performance of the developed correlation for wave velocity

To investigate the effect of diameter on the wave velocity, the results of the present work are combined with the results of Fukano et al. (1983), Paras and Karabelas (1991), and the correlations from Schubring and Shedd (2008) and Ousaka et al. (1992). Figure 10 presents the wave velocity variation for 6 different pipe diameters. It is obvious that the larger diameter results in the smaller wave velocity. The present results are in fairly good agreement with those resulted by Schubring and Shedd (2008) for the similar diameters. For $26 \mathrm{~mm}$ pipe, the mean absolute errors of this experiment are $11.8 \%, 11.3 \%$, and $10.4 \%$ for superficial liquid velocity of $0.05,0.1$, and $0.2 \mathrm{~m} / \mathrm{s}$, respectively. It gives an overall MAE of $11.2 \%$. The comparison with the correlation of Ousaka et al. (1992) gives larger MAE: $12.9 \%, 13.6 \%$, and $14.5 \%$ for the three superficial liquid velocities used in this experiment, or an overall MAE of $13.7 \%$. 


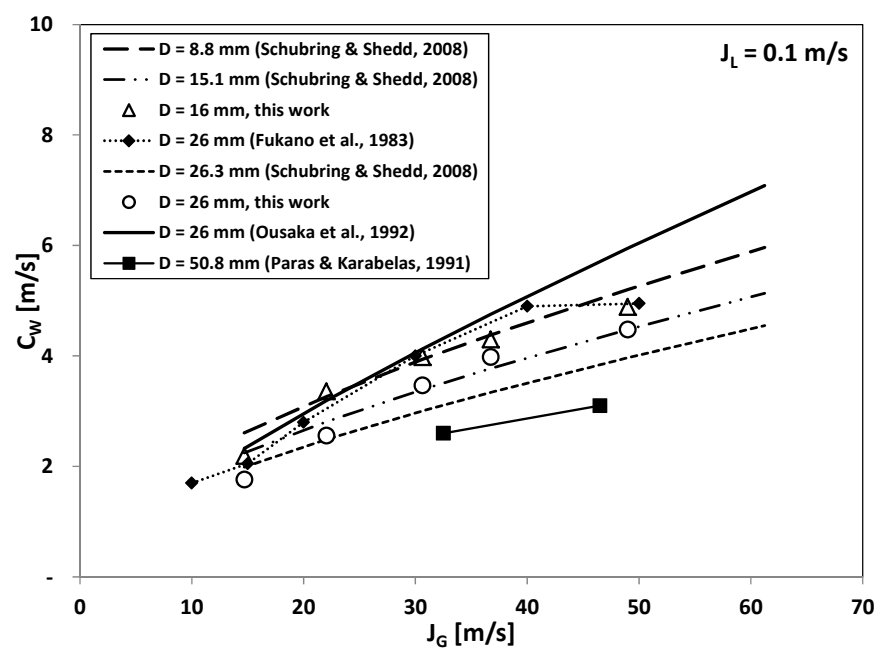

Figure 10. The effect of diameter on wave velocity

\subsection{Wave Frequency}

The wave frequency can be determined from the frequency corresponding to the largest peak of power spectral density function. Figure 11 shows the wave frequency plotted against superficial gas velocity for various superficial liquid velocities. It is obvious that the wave frequency decreases with the increase of the inner pipe diameter. In addition, the wave frequency increases with the increase of superficial gas velocity. It is in accordance with the experiment of Paras and Karabelas (1991), Jayanti et al., (1990), Fukano et al. (1983), and Schubring and Shedd (2008).

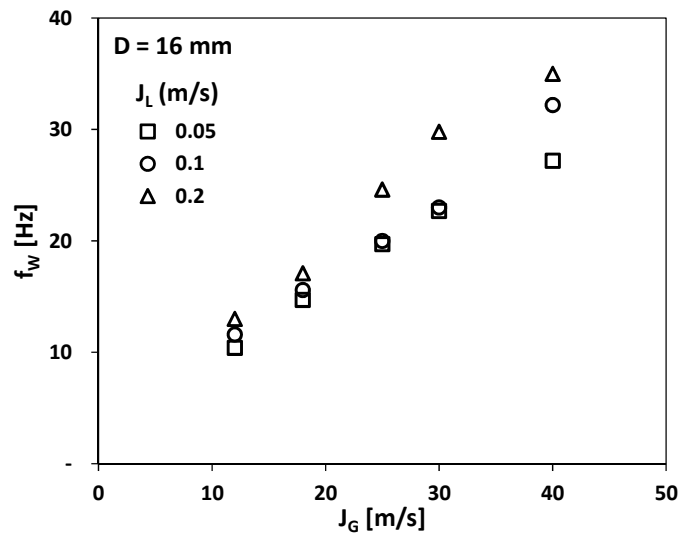

a. Inner diameter $=16 \mathrm{~mm}$

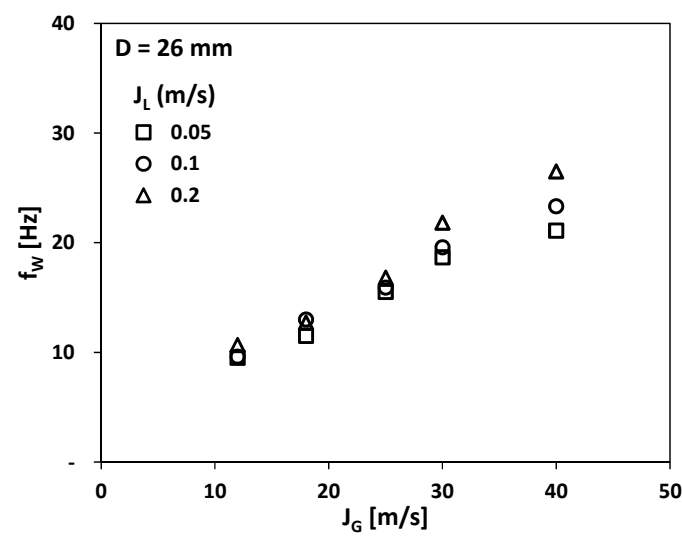

b. Inner diameter $=26 \mathrm{~mm}$

Figure 11. Wave frequency

As in the wave velocity, the effect of superficial liquid velocity on the wave frequency is also less significant compared to those of superficial gas velocity. In the present experimental study, multiplying the superficial gas velocity by a factor of 3.33 results in the increase of wave frequency by a factor of 2.69. Meanwhile, multiplying the superficial liquid velocity by a factor of 4 only results in the increase of frequency by a factor of 1.25 . The experiment of Schubring (2009) show that an increase of superficial gas velocity by a factor of 2.29 results in the increase of frequency by a factor of 1.83 for $15.1 \mathrm{~mm}$ pipe. For $26.3 \mathrm{~mm}$ pipe, increasing the superficial gas velocity by a factor of 1.99 results in the increase of frequency by a factor of 2.91 . This emphasizes the importance of superficial gas velocity on the wave frequency.

The insignificance of superficial liquid velocity could be seen by its little effect on the wave frequency. Increasing the superficial liquid velocity from 0.05 to $0.2 \mathrm{~m} / \mathrm{s}(400 \%$ from its original value) only gives an increase of wave frequency by a factor of 1.25 (or $25 \%$ increase in wave frequency). The previous work of Paras and Karabelas (1991), however, showed that the wave number decreases with the increase of superficial liquid velocity. The 
similar trend has also been proposed by Mantilla (2008) for low superficial gas velocity. To explain the difference of the results, he argued that as the superficial liquid velocity increase, the wave amplitude will also increase, thus more energy is required from the gas to keep the waves moving. Since the wave velocity is higher for higher superficial liquid velocity, then for constant gas velocity fewer waves or lower frequency are resulted due to energy conservation.

The correlations for the wave frequency have been developed by Schubring and Shedd (2008), in which the frequency is directly proportional to the superficial gas velocity. For experiment with $8.8 \mathrm{~mm}$ and $15.1 \mathrm{~mm}$ pipes, the correlation is

$$
f_{w}=0.005 \frac{J_{G}}{D \sqrt{x}}
$$

where $f_{w}$ is the wave frequency, $J_{G}$ is superficial gas velocity, $D$ is pipe diameter, and $x$ is the flow quality. For $26.3 \mathrm{~mm}$ pipe, the correlation is expressed as

$$
f_{w}=0.035 \frac{J_{G} \sqrt{F r_{\text {mod }}}}{D}
$$

where the modified Froude number, $F r_{\text {mod }}$, is defined by

$$
F r_{\text {mod }}=\frac{J_{G} \rho_{G}}{\rho_{L} \sqrt{g D}} .
$$

The similar correlation from Ousaka et al. (1992) is expressed as

$$
f_{w}=0.066 \frac{J_{L}}{D}\left(\frac{R e_{G}}{R e_{L}}\right)^{1.18} .
$$

Here, the effect of superficial gas and liquid velocities are expressed directly by $J_{L}$ and indirectly by the gas and liquid Reynolds numbers, $R e_{G}$ and $R e_{L}$. In comparison to the correlation of Schubring and Shedd (2008) for $16 \mathrm{~mm}$ pipe, the results of the present work give the mean absolute errors of of $22.2 \%, 10.2 \%$, and $11.9 \%$ for superficial liquid velocities of $0.05,0.1$, and $0.2 \mathrm{~m} / \mathrm{s}$, respectively. For $26 \mathrm{~mm}$ pipe, comparison to equation (5) for the given superficial liquid velocities gives larger errors: $28.4 \%, 28.9 \%$, and $31.5 \%$, respectively. The comparison with the correlation from Ousaka et al. (1992) for the given superficial liquid velocity gives MAE of 26.3\%, 14.0\%, and $21.7 \%$ for $16 \mathrm{~mm}$ pipe and $14.3 \%, 20.6 \%$, and $35.1 \%$ for $26 \mathrm{~mm}$ pipe.

To improve the performance of the prediction of wave frequency, a new correlation is developed following the model of Schubring and Shedd (2008). The best correlation resulted in this experiment for both pipe diameters, evaluated by the smallest MAE, is given by

$$
f_{w, \text { corr }}=0.035 \frac{J_{L}^{0.02} J_{G}^{0.9} F r_{m o d}^{0.25}}{D^{0.8} x^{0.25}}
$$

Here, superficial liquid velocity is involved in the correlation, although the effect is almost negligible. Using these correlations, the MAE for $16 \mathrm{~mm}$ pipe for the given superficial liquid velocities are 9.2\%, 9.6\%, and $3.6 \%$. For 26 mm pipe, the mean absolute errors are $6.4 \%, 8.7 \%$, and $14.0 \%$. The performance of the developed correlation for wave frequency is presented in Figure 12. 


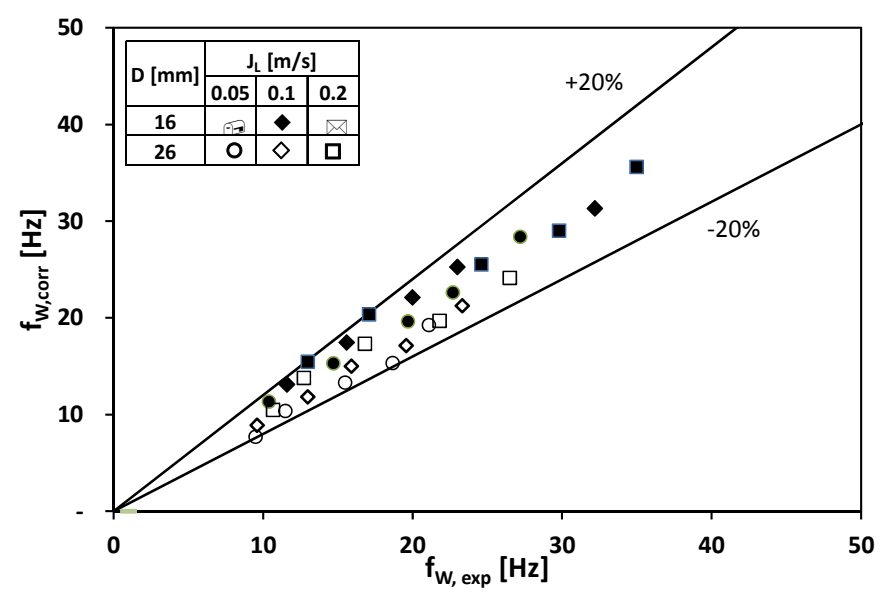

Figure 12. Performance of developed correlation for wave frequency

The effect of pipe diameter on the wave frequency is described in Figure 13 with a diameter range from $8.8 \mathrm{~mm}$ to $50.8 \mathrm{~mm}$. The wave frequencies for pipe diameters of $8.8 \mathrm{~mm}$ and $15.1 \mathrm{~mm}$ are obtained from the correlation of equation (4) and the frequency for $26.3 \mathrm{~mm}$ pipe is resulted from equation (5). From figure 13, it is apparent that the larger diameter gives the lower wave frequency. From equations (4) and (7), it is clearly shown that the dependence of wave frequency to the pipe diameter is inversely proportional. The involvement of the modified Froude number in Equation (5), however, shows that the effect of the pipe diameter is no longer inversely proportional for $26.3 \mathrm{~mm}$ pipe. This emphasizes that there is no agreement among the researchers in determining the effect of pipe diameter on the wave frequency.

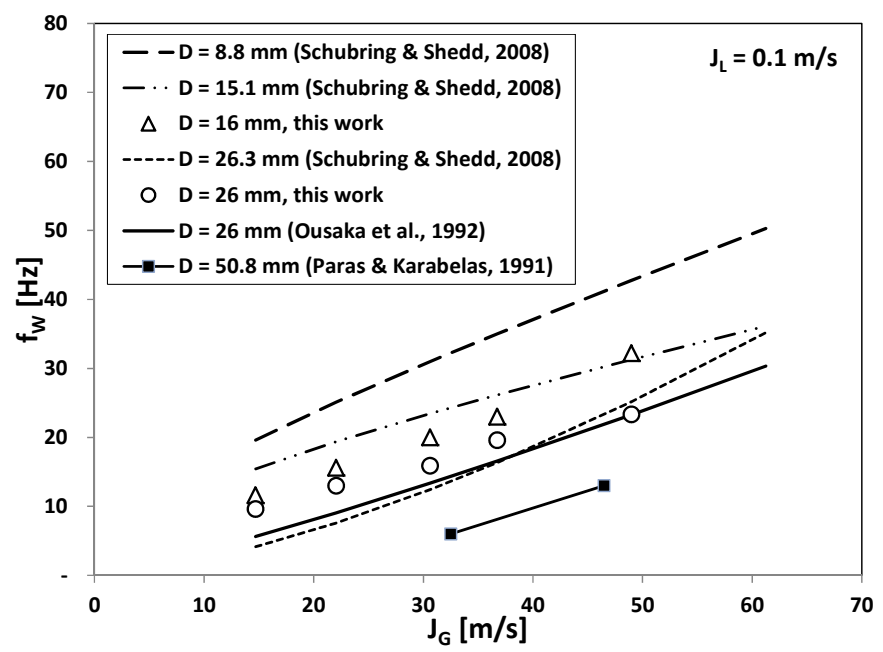

Figure 13. The effect of diameter on wave frequency

The ratio of velocity and length scales could be used for dimensional analysis of wave frequency, as suggested by Schubring (2009). In this case, the velocity scale is superficial gas velocity and the length scale is pipe diameter. From the experiment, the wave frequency tends to be approximately $1.1 \%$ of $J_{G} / D$. It means that this simple correlation is equivalent to assume a constant Strouhal number of 0.011 . This is slightly different to those of Schubring (2009), in which he suggested a value of $J_{G} / D=1 \%$. The mean absolute errors resulted from this correlation are $10 \%$ for $16 \mathrm{~mm}$ pipe and $22.9 \%$ for $26 \mathrm{~mm}$ pipe. Plot of wave frequency against $J_{G} / D$ is presented in Figure 14. 


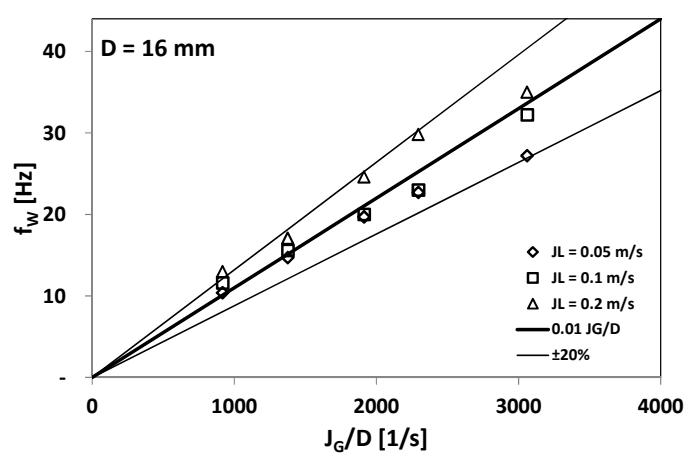

a. Inner diameter $=16 \mathrm{~mm}$

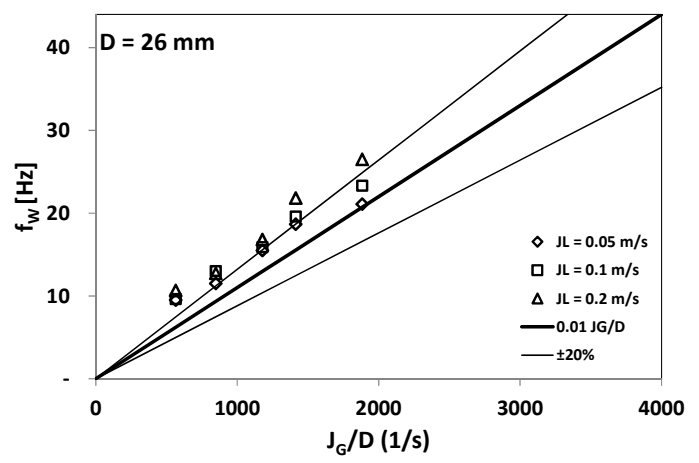

b. Inner diameter $=26 \mathrm{~mm}$

Figure 14. Wave frequency vs wave scale

To examine the proportionality of frequency to superficial gas velocity for constant diameter and liquid Reynolds number, a plot of Strouhal number, $S r$, against liquid film Reynolds number, $R e_{L, f i l m}$, is used. If frequency is proportional to superficial gas velocity, the plot of $S r$ against $\operatorname{Re}_{L, f i l m}$ would result in a line. Strouhal number and liquid film Reynolds number are defined as

$$
\begin{gathered}
S r=\frac{f_{w} D}{J_{G}} \\
R e_{L, f i l m}=\frac{\dot{m}_{L}}{D \pi \mu_{L}}
\end{gathered}
$$

where $\dot{m}_{L}$ is liquid mass flow rate and $\mu_{L}$ is liquid viscosity.

As shown in Figure 15, the proportionality of the wave frequency to superficial gas velocity could not be found in the present work and the proportionality of $16 \mathrm{~mm}$ pipe is better than that of $26 \mathrm{~mm}$ pipe. In general, the plot shows that the dependence of frequency on superficial gas velocity is non-linear, indicating that the effect of superficial gas velocity is not correctly predicted using velocity and length scales, as clearly shown in Figure 14.

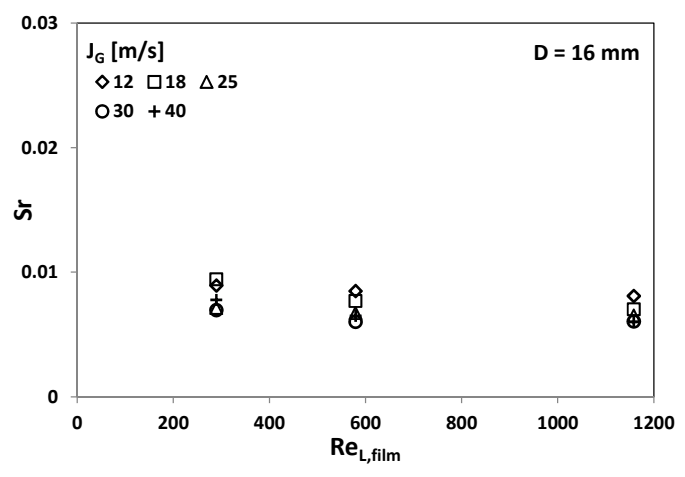

a. Inner diameter $=16 \mathrm{~mm}$

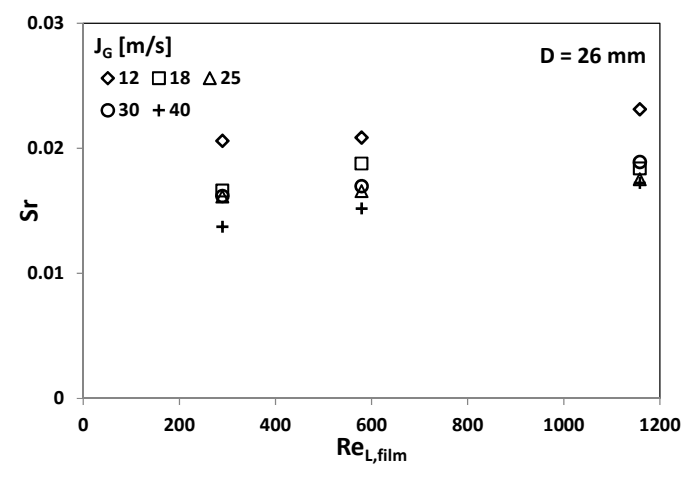

b. Inner diameter $=26 \mathrm{~mm}$

Figure 15. Wave Strouhal number vs liquid film Reynolds number

\section{Conclusion}

Experiment of air-water horizontal annular flow have been carried out using 16 and $26 \mathrm{~mm}$ pipe and both the transition of wavy-annular and fully developed annular flow have been successfully established. The common phenomena of annular flow such as ripple waves, disturbance waves, wave development and entrainment, coalescence, and breakup could be observed both visually and using liquid holdup signal. 
The effects of superficial gas velocity on wave velocity and frequency are clearly seen. The superficial liquid velocity, however, has a less significant effect on both wave characteristics. Correlations for wave velocity and frequency have been developed and both give reasonably good agreement with the experimental data.

Analysis using wave scale shows that the wave frequency tends to be approximately $1.1 \%$ of the ratio gas velocity to pipe diameter. The examination of the dependence of wave frequency on superficial gas velocity using plot of Strouhal number against liquid film Reynolds number, however, fail to show the linear proportionality of frequency to gas velocity.

\section{Acknowledgement}

The authors wish to thank Mr. Ade Indra Wijaya, the former student of the Department of Mechanical and Industrial Engineering, Gadjah Mada University, Indonesia, for his helpful support during the experiment in the Fluid Laboratory, Department of Mechanical and Industrial Engineering, Gadjah Mada University. Financial support from the Directorate General of Higher Education, the Ministry of Education and Culture of the Republic of Indonesia is also gratefully acknowledged.

\section{Reference}

Azzopardi, B. J. (1986). Disturbance wave frequencies, velocities and spacing in vertical annular two-phase flow. Nuclear Engineering and Design, 92(2), 121-133. http://dx.doi.org/10.1016/0029-5493(86)90240-2

Deendarlianto, Ousaka, A., Indarto, Kariyasaki, A., Lucas, D., Vierow, K., Vallee, C., \& Hogan, K. (2010). The effects of surface tension on flooding in counter-current two-phase flow in an inclined tube. Experimental Thermal and Fluid Science, 34, 813-826. http://dx.doi.org/10.1016/j.expthermflusci.2010.01.010

Deendarlianto, Ousaka, A., Kariyasaki, A., \& Fukano, T. (2005). Investigation of liquid film behavior at the onset of flooding during adiabatic counter-current air-water two-phase flow in an inclined pipe. Nuclear Engineering and Design, 235, 2281-2294. http://dx.doi.org/10.1016/j.nucengdes.2005.03.006

Fukano, T. (1998). Measurement of time varying thickness of liquid film flowing with high speed gas flow by CECM. Nuclear Engineering \& Design, 184, 363-377. http://dx.doi.org/10.1016/S0029-5493(98)00209-X

Fukano, T., Ousaka, A., Morimoto, T., \& Sekoguchi, K. (1983). Air-water annular two-phase flow in a horizontal tube $\left(2^{\text {nd }}\right.$ report, Circumferential variations of film thickness parameters). Bulletin of the JSME, 26(218). http://dx.doi.org/10.1299/jsme1958.26.1387

Han, H., Zhu, Z., \& Gabriel, K. (2006). A study on the effect of gas flow rate on the wave characteristics in two-phase gas-liquid annular flow. Nuclear Engineering and Design, 236, 2580-2588. http://dx.doi.org/10.1016/j.nucengdes.2006.03.015

Jayanti, S., Hewitt, G. F., \& White, S. P. (1990). Time-dependent behavior of the liquid film in horizontal annular flow. International Journal of Multiphase Flow, 16(6), 1097-1116. http://dx.doi.org/10.1016/0301-9322(90)90108-U

Lin, P. Y., \& Hanra'ity, T. J. (1987). Effect of pipe diameter on flow patterns for air-water flow in horizontal pipes. International Journal of Multiphase Flow, 13(4), 549-563. http://dx.doi.org/10.1016/0301-9322(87)90021-8

Mantilla, I. (2008). Mechanistic Modeling of Liquid Entrainment in Gas in Horizontal Pipes. Dissertation for Doctor of Philosophy in Petroleum Engineering, the University of Tulsa.

Ousaka, A., Deendarlianto, Kariyasaki, A., \& Fukano, T. (2006). Prediction of flooding gas velocity in gasliquid counter-current two-phase flow in inclined pipes. Nuclear Engineering and Design, 236, 1282-1292. http://dx.doi.org/10.1016/j.nucengdes.2005.12.001

Ousaka, A., Morioka, I., \& Fukano, T. (1992). Air-water annular two-phase flow in horizontal and near horizontal tubes: Disturbance wave characteristics and liquid transportation. Japanese Journal of Multiphase Flow, 6(9). http://dx.doi.org/10.3811/jjmf.6.80

Paras, S. V., \& Karabelas, A. J. (1991). Properties of the liquid layer in horizontal annular flow. International Journal of Multiphase Flow, 7(4), 439-454. http://dx.doi.org/10.1016/j.nucengdes.2005.12.001

Rodriguez, J. M. (2009). Numerical simulation of two-phase annular flow. Thesis for Doctor of Philosophy, Faculty of Rensselaer Polytechnic Institute.

Sawant, P., Ishii, M., Hazuku, T., Takamasa, T., \& Mori, M. (2008). Properties of disturbance waves in vertical annular two-phase flow. Nuclear Engineering and Design, 238, 3528-3541. 
http://dx.doi.org/10.1016/j.nucengdes.2008.06.013

Schubring, D. (2009). Behavior interrelationships in annular flow. Dissertation for Doctor of Phil. in Nuclear Engineering and Engineering Physics, University of Wisconsin-Madison.

Schubring, D., \& Shedd, T. A. (2008). Wave behavior in horizontal annular air-water flow. International Journal of Multiphase Flow, 34, 636-646. http://dx.doi.org/10.1016/j.ijmultiphaseflow.2008.01.004

Shedd, T. A. (2001). Characteristics of the liquid film in horizontal two-phase flow. Thesis for Doctor of Phil. in Mechanical Engineering, the University of Illinois at Urbana-Champaign.

Weisman, J., Duncan, D., Gibson, J., \& Crawford, T. (1979). Effects of fluid properties and pipe diameter on two-phase flow patterns in horizontal lines. International Journal of Multiphase Flow, 5, 437-462. http://dx.doi.org/10.1016/0301-9322(79)90031-4

Wilkes, N. S., Azzopardi, B. J., \& Thompson, C. P. (1983). Wave coalescence and entrainment in vertical annular two-phase flow. International Journal of Multiphase Flow, 9(4), 383-398. http://dx.doi.org/10.1016/0301-9322(83)90095-2

\section{Copyrights}

Copyright for this article is retained by the author(s), with first publication rights granted to the journal.

This is an open-access article distributed under the terms and conditions of the Creative Commons Attribution license (http://creativecommons.org/licenses/by/3.0/). 